\title{
A COMPARATIVE STUDY OF METABOLIC DISORDERS IN VERTIGO
}

\author{
Kamalini Bepari1 ${ }^{1}$ Siddharth Panditray², Shrabani Palai ${ }^{3}$, Bireswar Jyotishi ${ }^{4}$
}

${ }^{1}$ Assistant Professor, Department of ENT and Head Neck Surgery, VIMSAR, Burla.

2 Postgraduate Resident, Department of ENT and Head Neck Surgery, VIMSAR, Burla.

3 Postgraduate Resident, Department of SPM, MKCG, MCH, Berhampur.

${ }^{4}$ Postgraduate Resident, Department of ENT and Head Neck Surgery, VIMSAR, Burla.

\section{BACKGROUND}

ABSTRACT

Vertigo is a common medical condition, affecting around $1.8 \%$ of young adults to more than $30 \%$ in the elderly. Metabolic disorders commonly related to labyrinthine dysfunctions are glucose metabolism changes (diabetes, reactive hypoglycaemia and hyperinsulinaemia), thyroid hormones and lipid metabolism disorders.

The objective of this study is to compare the prevalence and association of metabolic disorders in vertigo cases to control under study.
\end{abstract}

\section{MATERIALS AND METHODS}

A case controlled study was done on patients presenting in ENT OPD, VIMSAR, Burla, with complaints of vertigo. 110 patients were chosen for the study between September 2015 and August 2017 and compared to age and gender matched controls (110). All patients and controls had the following blood investigations done: Fasting Blood Sugar (FBS), Oral Glucose Tolerance Test at 2 hrs. (OGTT2), thyroid profile (Free T3, Free T4, TSH) and Lipid Profile (Triglyceride (TG) and Low-Density Lipoprotein (LDL)). The metabolic disorders found were also compared to the ones found in the general population. The results were tabulated on excel sheets and statistical comparison and analysis was done with SPSS Version 16.0. Mann-Whitney U Test and chi-square test was applied for comparison. Statistical significance was set at $\mathrm{p}<0.05$.

\section{RESULTS}

The no. of vertigo patients with Type-2 diabetes mellitus were higher(1) in patients than controls.(2) Cases had more prevalence of thyroid disorders(3) than controls.(4) The incidence of abnormal lipid profile was higher in cases (35 cases with impaired TG, 27 cases with impaired LDL) than controls (17 each with impaired TG and LDL). The difference was significant in majority of parameters (FBS- $\mathrm{p}<0.015$; OGTT2- $\mathrm{p}<0.316$; T3- $\mathrm{p}<0.000$; T4- $\mathrm{p}<0.002$; TSH- $\mathrm{p}<0.000$; TG- $\mathrm{p}<0.003$; LDL- $\mathrm{p}<0.814$ ). The difference of diabetics and impaired glucose status in between cases of vertigo and controls are not statistically significant ( $p=0.770$, 目 $=0.086$, chi-square test). The difference is highly significant in between cases and controls of thyroid disorder ( $p=0.002$, ? = 14.66) and lipid disorder ( $\mathrm{p}=0.000$, 目= 12.53, chi-square test).

\section{CONCLUSION}

Metabolic impairments in vertigo are substantial and hence cannot be ignored in management. FBS, TSH, T3, T4, TG and LDL values of cases were impaired more than controls and the difference was statistically significant for FBS, TSH, T3, T4, TSH and TG. Cases in our study had significantly higher prevalence of thyroid and lipid disorders than controls. This study could be applied in management of patients with chronic vertigo by dietary therapy or hormone replacement.

\section{KEYWORDS}

Vertigo, Metabolic Disorders, Diabetic Vestibulopathy, Hypothyroid Vestibulopathy, Lipid Disorders in Vestibulopathy.

HOW TO CITE THIS ARTICLE: Bepari K, Panditray S, Palai S, et al. A comparative study of metabolic disorders in vertigo. J. Evolution Med. Dent. Sci. 2018;7(02):188-193, DOI: 10.14260/jemds/2018/42

\section{BACKGROUND}

Vertigo is a medical condition where a person feels as if they or the objects around them are moving when they are not. Often it feels like a spinning or swaying movement. This may be associated with nausea, vomiting, sweating or difficulty walking. It is typically worsened when the head is moved. Dizziness is impairment in spatial perception and stability. In the community, the prevalence of dizziness ranges from $1.8 \%$ in young adults to more than $30 \%$ in the elderly. ${ }^{5}$

'Financial or Other Competing Interest': None.

Submission 16-12-2017, Peer Review 28-12-2017,

Acceptance 30-12-2017, Published 08-01-2018.

Corresponding Author:

Siddharth Panditray,

Postgraduate Resident,

Department of ENT and Head Neck Surgery,

VIMSAR, Burla-768017, Odisha.

E-mail: siddoc786@gmail.com

DOI: $10.14260 /$ jemds $/ 2018 / 42$
Vertigo is associated with many metabolic disorders as accepted by many authors in the past. Metabolic disorders commonly related to labyrinthine dysfunctions are glucose metabolism changes (diabetes, reactive hypoglycaemia and hyperinsulinaemia),6,7,8 thyroid hormones $^{9}$ and lipid metabolism disorders. ${ }^{10,11}$

Reports linking glucose metabolism with inner ear diseases date back in time, but it was not until 1960 glucose was recognised as one of the main elements responsible for maintaining of the inner ear functional activity. ${ }^{12}$

Ischaemic changes in the levels of glucose, glycogen, ATP and P-creatine are determined under "closed system" conditions in the organ of Corti, stria vascularis, ganglion spirale, cochlear nerve and vestibular sensory epithelia. ${ }^{13}$ Immunohistochemistry approach has shown that the insulin receptor, insulin receptor substrate 1 (IRS1), protein kinase $B$ (PKB) and insulin-sensitive glucose transporter (GLUT4) are expressed in the sensory epithelium of the human saccule, 
which could explain link between diabetes and balance/hearing disorders. ${ }^{14}$ Hence, the hair cells and the central vestibular system are sensitive to diabetes mellitus secondary changes, particularly small changes in blood glucose and insulin in plasma. This is further supported by clinical trial of IGF-1 treatment on human SSHL as well as in vivo animal experiments, which has confirmed its efficacy in hair cell injuries. ${ }^{15}$ In a recent study, fractionated diet with glucose restriction was effective for the treatment of vestibular dysfunction associated with glucose metabolism disorders. ${ }^{16}$ Disorders of glucose metabolism are considered the most common aetiology of metabolic labyrinthine disorders as per previous studies.

Talking about lipid metabolism, the increase of cholesterol blood level (LDL) and triglycerides are reported as aetiological agents of labyrinthine disorders. ${ }^{11,4,17}$ While a greater prevalence of dyslipidaemia in sensorineural deafness patients is documented, ${ }^{18,19}$ more recent studies disprove of any link.20,21 One theory proposes that insulin and hyperinsulinaemia peripheral resistance would be responsible for increasing the production rate of triglycerides. ${ }^{22}$ Chronic dyslipidaemia associated with elevated triglycerides may reduce auditory function, shortterm dietary changes may not, 23 and lipid profile may not have a bearing on patients with idiopathic tinnitus. ${ }^{24}$ Importance of dietary management of dyslipidaemia has been stressed for management of BPPV in elderly. ${ }^{25}$

Hypothyroidism may be responsible for elevated levels of circulating lipids. Thyroid disorders have affected both central and peripheral vestibular disorders in various experimental studies.9,26 Thyroid hormone is suggested as a first transcriptional regulator of the motor protein prestin and as a direct or indirect modulator of subcellular prestin distribution 27 and autonomous functioning of TR $\alpha$ and TR $\beta$ in cochlear hair cells modulates active cochlear mechanics and inner hair cell output activity.28 In hypothyroidism, vasopressin levels fall and increase in hypothyroid cases. ${ }^{29}$ In contrast, aldosterone may be high in those who are hypothyroid due to the stimulating effect of TSH. ${ }^{30}$ Vasopressin and Aldosterone ultimately cause electrolyte imbalance and hence induce vertigo.

Because of the importance of metabolic disorders in the field of labyrinthine dysfunction and a few discrepancies in literature, we decided to carry out an observation of patients with vertigo and prevalence of metabolic disorders in them in Indian patients.

\section{Objective}

To compare the prevalence and association of metabolic disorders in vertigo cases to controls under study.

\section{MATERIALS AND METHODS}

110 patients presenting in the Department of ENT and HN Surgery, VIMSAR, Burla with complaints of dizziness, between September 2016 and August 2017 were taken up for the study. Informed consent was taken from all patients. Patients with history of head trauma, taking neuropsychiatric medications and on oral contraceptive pills were excluded from the study. The 110 controls chosen were age and gender matched individuals.

\section{Inclusion Criteria}

1. Patients presenting with dizziness, 2. Age between 20 and 70 years, 3 . Patients with informed consent for the study.

\section{Exclusion Criteria}

1. Patients with history of head trauma, 2. Intracranial tumours, 3. Patients on neuropsychiatric medications, 4. Patients on oral contraceptive pills, 5. Pregnancy.

In both groups, routine haematological investigations were carried out. Fasting blood sugar (FBS), Oral glucose tolerance test at 2 hours (OGTT2) with $75 \mathrm{mg}$ of glucose, Thyroid profile (Free T3, Free T4, TSH) and Lipid profile (Triglyceride (TG) and LDL fraction of cholesterol (LDL)) were the parameters considered for the study. The normal values considered for the study were-

\section{FBS}

Less than $110 \mathrm{mg} / \mathrm{dL} ; 111$ - 125 (impaired fasting glucose); 126 or more- Frank diabetes mellitus.

\section{OGTT2}

Less than $140 \mathrm{mg} / \mathrm{dL} ; 140$ - 199 (impaired); 200 or more frank diabetes.

\section{Thyroid Profile}

T3- (1.7-4.2) pg/mL; T4- (0.7-1.8) ng/ dL; TSH- (0.3-5.5) $\mu \mathrm{IU} / \mathrm{mL}$

\section{Lipid Profile}

TG- less than or equal to $150 \mathrm{mg} / \mathrm{dL}$; LDL- less than or equal to $130 \mathrm{mg} / \mathrm{dL}$.

The data was tabulated on Excel Sheets and SPSS version 17 was used for statistical analysis. Mann-Whitney U test was used for comparison to see the statistical difference between variable parameters like FBS, OGTT2, TG, LDL etc. in vertigo cases with controls taken for the study. $\mathrm{P}$ value $<0.05$ was taken as significant.

Chi-square test is used to see the association between metabolic disorders in vertigo cases with controls. $\mathrm{P}$ value $<0.05$ was taken to be significant.

\section{RESULTS}

Of the 110 patients and controls compared, 52 were males $(47.27 \%)$ and 58 were females $(52.73 \%)$ in cases and 50 were males (45.45\%) and 60 were females (54.55\%) in controls. The average age of the study group was 49.80 years and control group was 42.99 years.

The difference of FBS in case and controls were found to be significant $(\mathrm{p}=0.015)$, but the difference in OGTT2 was not found to be significant $(\mathrm{p}=0.316)$.

Of the cases 14 subjects (12.72\%) had frank diabetes, while 7 (6.36\%) individuals in controls had diabetes mellitus 2. The prevalence in general population is around $7.1 \%$ to $8.7 \%$ as per various studies. 31

Impaired glucose tolerance was found in 25 cases $(22.72 \%)$ and 15 controls (13.63\%). The difference of levels of T3 $(\mathrm{p}=0.00), \mathrm{T} 4(\mathrm{p}=0.002)$ and TSH $(\mathrm{p}=0.00)$ between cases and controls were found to be highly significant. 
The difference of diabetics and impaired glucose status in between cases of vertigo and controls are not statistically significant $(p=0.770$, ? $=0.086$, chi-square test $)$.

Thyroid disorders were found in 25 cases $(22.72 \%)$ and 12 controls $(10.90 \%)$. The incidence of thyroid disorders in Indian population is close to $11 \% .32$

14 of the 25 cases (56\%) and 7 of 12 controls (58.3\%) were subclinical hypothyroid states. Subclinical hypothyroidism is the most prevalent thyroid disorder affecting $3 \%-15 \%$ of the adult population. ${ }^{33}$ Subclinical cases constituted $12.7 \%$ of sample size and $6.3 \%$ of controls, depicting similar levels to general population.

The difference of TG was significant in cases and controls $(p=0.003)$, whereas the difference was not significant in case of LDL $(\mathrm{p}=0.81)$.
Lipid abnormalities with increased TG levels were seen in 35 cases $(31.81 \%)$ and 17 controls $(15.45 \%)$ and increased LDL were seen in 27 cases (24.54\%) and 17 controls $(15.45 \%)$.

The difference is highly significant in between cases and controls of thyroid disorder $(\mathrm{p}=0.002$, $\mathrm{?}=14.66)$ and lipid disorder ( $p=0.000$, ? = 12.53), chi-square test).

Recent reviews have reported that high cholesterol is present in $25 \%-30 \%$ of urban and $15 \%-20 \%$ of rural subjects. ${ }^{34}$

Combined TG and LDL increase was seen in 19 cases $(17.27 \%)$ and 3 controls $(2.72 \%)$.

Comparing the mean of individual parameters in cases and controls, we found a statistically significant difference in most.

\begin{tabular}{|l|c|c|c|c|c|c|c|}
\hline \multicolumn{8}{|c|}{ Mean \pm Standard Deviation of Individual Parameters of the Study } \\
\hline & FBS & OGTT2 & T3 & T4 & TSH & TG & LDL \\
\hline \multirow{2}{*}{ Cases } & $99.091 \pm$ & $134.891 \pm$ & $2.4922 \pm$ & $1.1395 \pm$ & $5.1897 \pm$ & $137.0 \pm$ & $119.109 \pm$ \\
\cline { 2 - 8 } & 20.4103 & 27.3282 & 0.92 & 0.462 & 4.448 & 35.657 & 22.346 \\
\hline \multirow{2}{*}{ Controls } & $93.518 \pm$ & $134.927 \pm$ & $2.9141 \pm$ & $1.2710 \pm$ & $2.7562 \pm$ & $123.91 \pm$ & $115.836 \pm$ \\
\cline { 2 - 8 } & 17.6753 & 21.3858 & 0.984 & 0.374 & 2.646 & 25.667 & 20.824 \\
\hline
\end{tabular}

From the above table, it is clear that the levels of FBS in cases was higher suggesting impaired carbohydrate metabolism in patients with dizziness. The levels of thyroid hormones were lower and TSH was higher in cases suggesting a higher prevalence of hypothyroid states in patients. TG and LDL levels were also higher in patients suggesting dyslipidaemia as a contributor to disease pathogenesis.

Table 2 and 3. Median and IQR values of Cases and Controls

\begin{tabular}{|c|c|c|}
\hline & MEDIAN & IQR \\
\hline FBS & 98 & $87-115.5$ \\
\hline OGTT2 & 128 & $115.7-144.2$ \\
\hline TG & 134 & $109.7-158$ \\
\hline LDL & 114.5 & $104-128.5$ \\
\hline T3 & 2.4 & $1.8-3.1$ \\
\hline T4 & 1.19 & $.86-1.38$ \\
\hline TSH & $4.49 \quad$ Table 2. For Cases & $2.8-5.4$ \\
\hline \multicolumn{2}{|c|}{} \\
\hline
\end{tabular}

\begin{tabular}{|c|c|c|}
\hline & MEDIAN & IQR \\
\hline FBS & 92 & $18.7-105.5$ \\
\hline OGTT2 & 129 & $105.7-138$ \\
\hline TG & 119.5 & $107.7-122$ \\
\hline LDL & 119.5 & $2.2-3.63$ \\
\hline T3 & 2.94 & $1.15-1.46$ \\
\hline TS & 1.32 & $0.96-3.31$ \\
\hline
\end{tabular}

The difference was significant in the following parameters

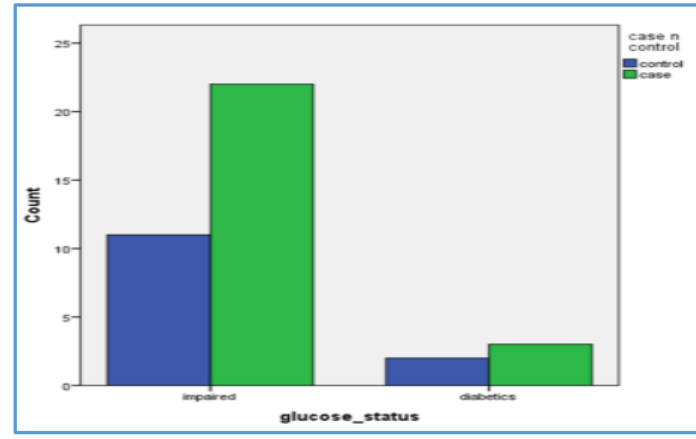

Figure 1. Graphical Representation comparing Diabetics and Impaired Glucose Status (More Prevalence in Cases than Controls)

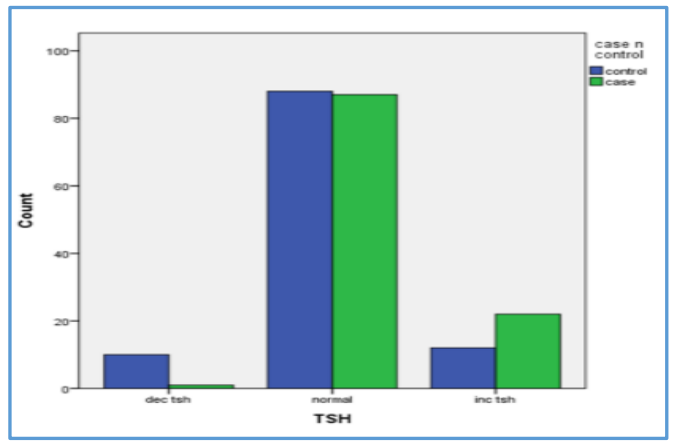

Figure 2. Graphical Representation comparing Hypothyroid, Hyperthyroid and Euthyroid States (In Terms of TSH) in Cases and Controls showing more Prevalence of Hypothyroid States in Cases 


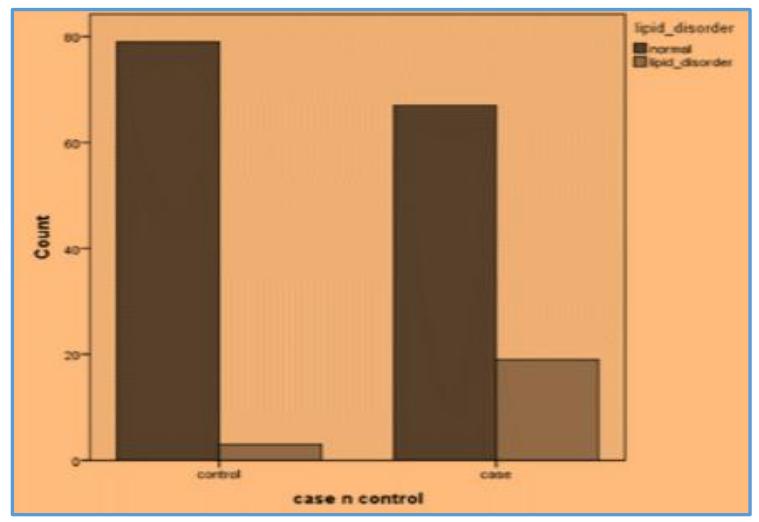

Figure 3. Graphical Representation comparing Prevalence of Lipid Disorders (More in Cases than Controls)

\section{DISCUSSION}

Inner ear, despite being considered a physiological masterpiece, is subject to influence and regulation by various metabolic mechanisms.

Evidence suggests that the stria is the site of intense metabolic activity in the labyrinth. ${ }^{35,36}$ A study revealed vestibular caloric stimulation (CS) inhibited noradrenergic (NA) neurons of the locus coeruleus (LC) in rats and hence speculating that LC-NA inhibition participates in the development of sensory mismatch during vertigo and motion sickness. ${ }^{37}$ In diabetes mellitus, the observed changes are microangiopathy and peripheral neuropathy with consequent terminal blood flow problems and irregular supply of glucose.10,2 Some authors also reported minimal cellular changes and central vestibular system functional impairment as a complication of early diabetes mellitus, even without neuropathy or microangiopathy.8,38,39 There are no tissue reserves of energy in the labyrinth and its ongoing activity makes it sensitive to variations of glucose supply during hypoglycaemia or in the presence of high insulin levels. ${ }^{7,40}$ In a study subjecting cases to a 5-hour glucose tolerance test with simultaneous titration of insulin, it was found that $82 \%$ of the patients presented abnormal glucose and/or insulin values responding well to diet on followup. ${ }^{41,42}$ Also, hyperglycaemia and thyroid disorders (discussed later) are much more frequent in patients with sudden deafness than in the general population and should be considered as important associated risk factors. ${ }^{18}$ Of the cases in our study 14 subjects $(12.72 \%)$ had frank diabetes, while $7(6.36 \%)$ individuals in controls had diabetes mellitus 2, agreeing with previous studies. ${ }^{43}$ Prevalence of diabetes in cases was also lower than general population. Impaired glucose tolerance was found in 25 cases $(22.72 \%)$ and 15 controls $(13.63 \%)$ coinciding with results of previous studies. ${ }^{44}$ A study of biopsies of jejunal mucosa revealed abnormal enzyme activity or deficiencies in transport mechanisms of glucose, which further lays importance on close follow-up and dietary management options in managing vertigo in patients with impaired glucose tolerance. 45

Variations in blood viscosity can compromise terminal flow into the cochlea, hampering oxygen supply required for $\mathrm{Na} / \mathrm{K}$ system operation and maintenance of end cochlear potential.11,4 Besides this effect, the metabolism of lipids is directly associated with that of insulin $46,1,47$ and the association between lipid and carbohydrate disorders in patients with vertigo is related to increased risk of atherosclerosis or myocardial infarction. ${ }^{11,4}$ Serum cholesterol and hyperlipidaemia as an aetiology of the atherosclerosis of all blood vessels also have a role in vestibule-cochlear vessels and usually above the age of 40 yrs. $^{3}$ Chronic hypercholesterolaemia with alterations in both the stria vascularis and outer hair cells metabolically stresses inner ear tissue increasing susceptibility to ototraumatic agents. ${ }^{48}$ Our study found lipid abnormalities with increased TG levels were seen in $31.81 \%$ cases vs. $15.45 \%$ controls, and increased LDL were seen in $24.54 \%$ cases and $15.45 \%$ controls. This was more than the prevalence in general population. Combined TG and LDL increase was seen in $17.27 \%$ cases vs. $2.72 \%$ controls. The difference was significant for triglycerides in contrast to other studies, which found out higher rates of LDL disorders with normal triglyceride levels ${ }^{49}$ or lower than population levels. ${ }^{50}$ Thus, the role of triglycerides is still unclear and needs to be investigated further.

Studies assessing thyroid dysfunctions and the inner ear are still rare. ${ }^{51}$ However, it was experimentally demonstrated that presence of the alpha and beta specific receptors for the thyroid hormone in the ear of mice are essential for its maturation. ${ }^{52}$ Thyroid hormones are responsible for the performance of prestin protein directly linked to the outer hair cells activity as seen in rats. Absence of thyroid hormone stimulation impairs neural stimulus conduction in the central vestibular system. 53 Our study found out thyroid disorders based on TSH levels, which were found in $22.72 \%$ cases and $10.90 \%$ controls. Thyroid disorders in Indian population exhibit lesser prevalence than our cases. Studies have shown subjective improvement of all symptoms in Meniere's disease with hypothyroidism after 12 weeks of treatment. ${ }^{54}$ Thyroid and lipid disorders showed statistically significant difference in our study, but diabetes and impaired glucose status were not significantly higher in cases in our study.

\section{CONCLUSION}

Metabolic impairments in vertigo are substantial and hence cannot be ignored in management. FBS, TSH, T3, T4, TG and LDL values of cases were impaired, more than controls and the difference was statistically significant for FBS, TSH, T3, T4, TSH and TG. Cases in our study had significantly higher prevalence of thyroid and lipid disorders than controls. This study could be applied in management of patients with chronic vertigo by dietary therapy or hormone replacement.

\section{REFERENCES}

[1] Van Gaal LF, Nobels FR, Rillaerts EG, et al. Hypertension in obese and non-obese non-insulindependent diabetics a matter of regional adiposity? Diab Metab 1988;14(3):289-93.

[2] Rask-Madsen C, King GL. Mechanisms of disease: endothelial dysfunction in insulin resistance and diabetes. Nat Clin Pract Endocrinol Metab 2007;3(1):46-56.

[3] Maru YK, Jain N. Lipid profile studies in inner ear dysfunction. Indian J Otolaryngol Head Neck Surg 1994;46(1):17-20. https://doi.org/10.1007/BF0305007.

[4] Friedrich G, Pilger E. Lipoproteins in cochleovestibular disorders. Arch Otorhinolaryngol 1981;232(2):101-5.

[5] Sloane PD, Coeytaux RR, Beck RS, et al. Dizziness: state of the science. Ann Intern Med 2001;134(9 Pt 2):82332. 
[6] Sanchez TG, Medeiros IRT, Coelho FF, et al. Frequência de alterações da glicose, lipídeos e hormônios tireoideanos em pacientes com zumbido. Arq Otorrinolaringol 2001;5(1):6-10.

[7] Doroszewska G, Kazmierczak H. Hyperinsulinemia in vertigo, tinnitus and hearing loss. Otolaryngol Pol 2002;56(1):57-62.

[8] Lisowska G, Namyslowski G, Morawski K, et al. Early identification of hearing impairment in patients with type 1 diabetes mellitus. Otol Neurotol 2001;22(3):316-20.

[9] Modugno GC, Pirodda A, Ferri GG, et al. A relationship between autoimmune thyroiditis and benign paroxysmal positional vertigo? Med Hypotheses 2000;54(4):614-5.

[10] Bittar RSM, Sanchez TG, Santoro PP, et al. O metabolismo da glicose e o ouvido interno. Arq Otorrinolaringol 1998;2(1):39-44.

[11] Saito T, Sato K, Saito H. An experimental study of auditory dysfunction associated with hyperlipoproteinemia. Arch Otorhinolaryngol 1986;243(4):242-5.

[12] Koide Y, Tajima S, Yoshida M, et al. Biochemical changes in the inner ear induced by insulin, in relation to the cochlear microphonics. Ann Otol Rhin Laryngol 1960;69:1083-97.

[13] Thalmann R, Miyoshi T, Thalmann I. The influence of ischemia upon the energy reserves of inner ear tissues. The Laryngoscope 1972;82(12):2249-72.

[14] Degerman E, Rauch U, Lindberg S, et al. Expression of insulin signalling components in the sensory epithelium of the human saccule. Cell Tissue Res 2013;352(3):469-78.

https://doi.org/10.1007/s00441-013-1614-x

[15] Yamamoto N, Nakagawa T, Ito J. Application of insulinlike growth factor- 1 in the treatment of inner ear disorders. Frontiers in Pharmacology 2014;5:208.

[16] Bittar RSM, Santos MA, Mezzalira R. Glucose metabolism disorders and vestibular manifestations: evaluation through computerized dynamic posturography. Braz J Otorhinolaryngol 2016;82(4):372-6.

[17] Lin ZM, Young YH. Investigating the causes of vertigo in breast cancer survivors. Eur Arch Otorhinolaryngol 2005;262(5):432-6.

[18] Oiticica J, Bittar RSM. Metabolic disorders in sudden deafness. Clinics (Sao Paulo) 2010;65(11):1149-53.

[19] Jones NS, Davis A. A retrospective case-controlled study of 1,490 consecutive patients presenting to a neuro-otology clinic to examine the relationship between blood lipid levels and sensorineural hearing loss. Clin Otolaryngol Allied Sci 2000;25(6):511-7.

[20] Kim DH, Park SK, Kim KM, et al. Association between hearing loss and dyslipidemia prevalence and treatment in adults in Korea: the fifth Korean National Health and Nutrition Examination Survey in 2010? 2012. Korean J Fam Pract 2016;6(4):235-41. https://doi.org/10.21215/kjfp.2016.6.4.235

[21] Odeh OI, Kuti MA, Fasunla AJ, et al. Sensorineural hearing loss and dyslipidemia: Is there any relationship? West African Journal of Medicine 2015;34(1):27-31.
[22] Olefsky JM, Farquhar JW, Reaven GM. Reappraisal of the role of insulin in hypertriglyceridemia. Am J Med 1974;57(4):551-60.

[23] Evans MB, Tonini R, Shope CD, et al. Dyslipidemia and auditory function. Otol 2006;27(5):609-14.

[24] M-Shirazi M, Farhadi M, Jalessi M, et al. Prevalence of dyslipidemia among Iranian patients with idiopathic tinnitus. Journal of Research in Medical Sciences 2011;16(7):890-6.

[25] Schultz AR, Neves-Souza RD, Costa Vde S, et al. Is there a possible association between dietary habits and benign paroxysmal positional vertigo in the elderly? The importance of diet and counseling. Int Arch Otorhinolaryngol 2015;19(4):293-7.

[26] Bhatia PL, Gupta OP, Agrawal MK, et al. Audiological and vestibular function tests in hypothyroidism. Laryngoscope 1977;87(12):2082-9.

[27] Weber T, Zimmermann U, Winter H, et al. Thyroid hormone is a critical determinant for the regulation of the cochlear motor protein prestin. Proc Natl Acad Sci U. S. A. 2002;99(5):2901-6. www.pnas.org.

[28] Dettling J, Franz C, Zimmermann U, et al. Autonomous functions of murine thyroid hormone receptor TR $\alpha$ and TR $\beta$ in cochlear hair cells. Mol Cell Endocrinol 2014;382(1):26-37. https://doi.org/10.1016/j.mce.2013.08.02

[29] Murgod R, Soans G. Changes in electrolyte and lipid profile in hypothyroidism. Life Science Bio Chemistry 2012;2(3):185-94.

[30] Arnaout MA, Awidi AS, El-Najdawi AM, et al. Argininevasopressin and endothelium-associated proteins in thyroid disease. Acta Endocrinol (Copenh) 1992;126(5):399-403.

[31] https://www.idf.org/our-network/regionsmembers/south-east-asia/.../94-india.html.

[32] Bagcchi S. Hypothyroidism in India: more to be done. The Lancet Diabetes \& Endocrinology 2014;2(10): p. 778.

[33] Ayala AR, Danese MD, Ladenson PW. When to treat mild hypothyroidism. Endocrinol Metab Clin North Am 2000;29(2):399-415.

[34] Gupta R, Rao RS, Misra A, et al. Recent trends in epidemiology of dyslipidemias in India. Indian Heart J 2017;69(3):382-92.

https://doi.org/10.1016/j.ihj.2017.02.020

[35] Angeli RD, Lavinski L, Dolganov A. Alterations in cochlear function during induced acute hiperinsulinemia in animal model. Braz J Otorhinolaryngol 2009;75(5):760-4.

[36] Bittar RSM, Bottino MA, Simoceli L, et al. Vestibular impairment secondary to glucose metabolic disorders: reality or myth? Rev Braz Otorhinolaryngol 2004;70(6):800-5.

[37] Nishiike S, Takeda N, Kubo T, et al. Noradrenergic pathways involved in the development of vertigo and dizziness--a review. Acta Otolaryngol Suppl 2001;545:61-4.

[38] Hosch H, Ottaviani F. Otoacustic emissions in diabetic patients with normal hearing. Schweiz Med Wochenschr 2000; Suppl 125:S83-S5. 
[39] Lisowska G, Namyslowski G, Morawski K, et al. Cochlear dysfunction and diabetic microangiopathy. Scand Audiol Suppl 2001;(52):199-203.

[40] Fukuda Y. Glicemia, insulinemia e patologia da orelha interna. São Paulo 1982. (Tese de Doutorado, Escola Paulista de Medicina).

[41] Albernaz MPL, Fukuda Y. Glucose, insulin and inner ear pathology. Acta Otolaryngol 1984;97(5-6):496501.

[42] Lehrer JF, Poole DC, Seaman M, et al. Identification and treatment of metabolic abnormalities in patients with vertigo. Arch Intern Med 1986;146(8):1497-500.

[43] Charles DA, Barber HO, Hope-Gill HF. Blood glucose and insulin levels, thyroid function and serology in Ménière's disease, recurrent vestibulopathy and psychogenic vertigo. J Otolaryngology 1979;8(4):34753.

[44] Kaźmierczak H, Doroszewska G. Metabolic disorders in vertigo, tinnitus and hearing loss. The International Tinnitus Journal 2001;7(1):54-8.

[45] Mangabeira-Albernaz, Luiz $P$, et al. Vestibular disorders caused by defective enzyme mechanisms in the small intestine. Acta Oto-laryngologica 1985;99.34:330-5.

[46] Braverman LE, Utiger RD. The Thyroid. Chap 62. A fundamental and clinical text. 7th edn. Philadelphia: Lippincott-Raven Publishers 1996.
[47] Savage DB, Petersen KF, Shulman GI. Disordered lipid metabolism and the pathogenesis of insulin resistance. Physiol Rev 2007;87(2):507-20.

[48] Gratton MA, Wright CG. Alterations of inner ear morphology in experimental hypercholesterolemia. Hearing Research 1992;61(1-2):97-105.

[49] Zielinska-Blizniewska H, Urbaniak J, Jałocha-Kaczka A, et al. Lipid disorders in patients with vertigo. Aktualnosci Neurologiczne 2012;12(3):143-8.

[50] Santos MD, Bittar RS. Vertigo and metabolic disorders. International Tinnitus Journal 2012;17(1):16-20.

[51] Brenner M, Hoistad DL, Hain TC. Prevalence of thyroid dysfunction in patients with Ménière's disease. Arch Otolaryngol Head Neck Surg 2004;130(2):226-8.

[52] Bradley DJ, Towle HC, Young WS. Alpha and beta thyroid hormone receptor (TR) gene expression during auditory neurogenesis: evidence for TR isoform-specific transcriptional regulation in vivo. Proc Natl Acad Sci USA 1994;91(2):439-43.

[53] Meza G, Acuna D, Escobar C. Development of vestibular and auditory function: effects of hypothyroidism and thyroxin replacement therapy on nystagmus and auditory evoked potentials in the pigmented rat. Int J Dev Neurosci 1996;14(4):515-22.

[54] Santosh UP, Rao MS. Incidence of Hypothyroidism in Meniere's disease. Journal of Clinical and Diagnostic Research 2016;10(5):MC01-3. 